\title{
Mitotic Rate Score 2
}

National Cancer Institute

\section{Source}

National Cancer Institute. Mitotic Rate Score 2. NCI Thesaurus. Code C138984.

A finding of 4-7 mitoses per mm2 (8-14 per $10 \mathrm{hpf}$ ). 